Syst (2005) 21:128-132. DOI 10.1007/s00381004-1036-x

5. Ahmad Faried và cộng sự (2019), Correlation between the skull base fracture and the incidence of intracranial hemorrhage in patients with traumatic brain injury. Chinese Journal of Traumatology.Volume 22, Issue 5, October 2019, Pages 286-289. DOI: 10.1016/j.cjtee.2019.05.006

\title{
ĐÁNH GIÁ KẾT QUẢ SỚM PHẪU THUÂTT UNG THƯ ĐẠI TRÀNG PHẢI TẠI BỆNH VIỆN ĐA KHOA TİNH NAM ĐİNH GIAI ĐOẠN 2018 - 2020
}

\author{
Bùi Văn Ngọc1, Kim Văn Vụ², \\ Hoàng Ngọc Hà ${ }^{1}$, Đào Trường Minh ${ }^{1}$
}

\section{TÓM TẮT}

Mục tiêu: Đánh giá kết quả sớm phẫu thuật ung thư đại tràng phải (UTĐTP) tại Bệnh viện Đa khoa tỉnh Nam Định giai đoạn 2018 - 2020.Đối tượng và phương pháp: Nghiên cứu mô tả cắt ngang được tiến hành trên 41 bênh nhân UTĐTP tại Bệnh viện Đ̇a khoa tỉnh Nam Định từ tháng $1 / 2018$ đến tháng 12/2020. Thu thâp số liêu qua hồ sơ bệnh án ghi nhân các đặc điểm chung, lâm sàng, cận lâm sằng, đặc điểm phấu thuât, tai biến và biến chứng phẩu thuật. Kết quả: Tuổi trung bình $62,9 \pm 18,4$ tuổi. Nữ $(63,4 \%)$ nhiều hơn nam $(36,6 \%)$. Kích thước u $6,4 \pm$ $1,9 \mathrm{~cm}$. Có $82,9 \%$ trường hợp u đã xâm lấn qua thành đại tràng, 39,5\% trường hợp di căn hạch. Giai đoạn I, II, III trong 38 trường hợp được đếm hạch lần lượt là $5,3 \%, 55,3 \%, 39,4 \%$. Thời gian mổ trung bình122,6 \pm 28,5 phút, dùng giảm đau sau mổ $3,8 \pm 0,7$ ngày, có nhu động ruột sau mổ $3,1 \pm 0,6$ ngày, thời gian nằm viện trung bình sau mô $10,6 \pm 2,8$ ngày, $14,6 \%$ bi nhiễm trùng vết mổ và $2,4 \%$ bị bí tiểu. Kết luận: Phẫu thuật cắt đại tràng phải do ung thư đại trà̀ng phải tại Bệnh viện Đa khoa tỉnh Nam Định giai đoạn 2018-2020 cho kết quả sớm tương đối tốt.

Tư khóa: kết quả sớm, phẫu thuật, ung thư đại tràng phải.

\section{SUMMARY}

EVALUATION OF EARLY RESULTS RIGHT COLON CANCER SURGERY AT NAM DINH PROVINCIAL GENERAL HOSPITAL FROM 2018 TO 2020

Objective: Evaluate the early results of surgery for right colon cancer at Nam Dinh General Hospital from 2018 to 2020. Objects and Methods: Crosssectional descriptive study was conducted on 41 patients with right colon cancer at Nam Dinh Provincial General Hospital from January 2018 to December 2020. Data collection through medical records including general characteristics, clinical characteristics, subclinical, surgical features,

\footnotetext{
${ }^{1}$ Bệnh viện đa khoa tỉnh Nam Định

${ }^{2}$ Trường Đại học Y Hà Nội

Chịu trách nhiệm chính: Bùi Văn Ngọc

Email: buivanngocdknd@gmail.com

Ngày nhận bài: 2.6.2021

Ngày phản biên khoa họ: 31.7.2021

Ngày duyệt bài: 10.8.2021
}

complications and complications of surgery. Results: Average age $62.9 \pm 18.4$ years. Women $(63.4 \%)$ are higher than men $(36.6 \%)$. Tumor size $6.4 \pm 1.9 \mathrm{~cm}$ There are $82.9 \%$ of cases where the tumor has invaded through the colon, $82,9 \%$ of cases have lymph node metastasis (15/38 cases). The stages of the disease I, II, III are 5,3\%, 55,3\%, 39,4\%. The average surgery time $122.6 \pm 28.5$ minutes, used for postoperative pain relief $3.8 \pm 0.7$ days, have peristalsis after surgery $3.1 \pm 0.6$ days, hospital stay after surgery $10.6 \pm 2.8$ days, $14.6 \%$ of cases were wound infection and $2.4 \%$ of cases of urinary retention. Conclusion: Surgery to remove the right colon cancer at Nam Dinh general hospital in 20182020, the early results are relatively good.

Keyword: early outcomes, surgery, right colon cancer.

\section{I. ĐăT VẤN ĐỀ}

Ung thư đại trực tràng là ung thư phổ biến thứ 3 ở nam giới và đứng thứ 2 ở nữ. Tại Việt Nam, theo số liệu năm 2018 trên cả nước có khoảng 14.733 người mới mắc đứng thứ tư ở nam và thứ hai ở nữ, 7.856 người tử vong [6]. UTĐTP chiếm khoảng $25 \%$ các trường hợp ung thư đai tràng [8].

Điều trị UTĐTP hiện nay phẫu thuật vẫn là phương pháp điều trị chính để lấy bỏ u nguyên phát và vét hạch vùng, đánh giá giai đoạn sau mổ để có phương án điều trị bổ trợ hợp lý. Tại Việt Nam đã có một số công trình nghiển cứu về chẩn đoán và điều trị UTĐTP. Tại Nam Định, phẫu thuật UTĐTP đã được thực hiện nhiều năm nay, tuy nhiên chưa có bất kỳ môt nghiên cứu nào về đánh giá kết quả điều trị phẫu thuật.

Xuất phát từ vấn đề trên, chúng tôi thực hiện nghiên cứu nàyvới mục tiêu: Đánh giá kết quả sớm phẫu thuật UTĐTP tại Bệnh viện Đa khoa tỉnh Nam Định giai đoạn 2018 - 2020.

\section{II. ĐỐI TƯợNG VÀ PHƯƠNG PHÁP NGHIÊN CỨU}

2.1. Đối tượng nghiên cứu. Nghiên cứu bao gồm 41 bệnh nhân UTĐT phải được phẫu thuật cắt đại tràng phải tại Bệnh viện Đa khoa tỉnh Nam Định trong thời gian từ tháng 1/2018 đến hết tháng 12/2020. 
- Tiêu chuẩn lựa chon bệnh nhân

+ Bệnh nhân được chẩn đoán xác định là UTĐT phải nguyên phát được phẫu thuật cắt đại tràng phải tại Bệnh viện Đa khoa tỉnh Nam Định.

+Có đầy đủ hồ sơ bênh án với các xét nghiệm để chẩn đoán trước, trong và sau mổ.

+Có đầy đủ các thông tin kiểm tra và theo dõi sau phẫu thuật.

\section{- Tiêu chuẩn loai trừ}

+ Không có đầy đủ hồ sơ bệnh án.

+ Không có kết quả giải phẫu bệnh sau phẫu thuật hoặc kết quả giải phẫu bệnh không phải là UTĐT phải.

+ Mắc một bệnh lý ung thư khác: Ung thư phổi, ung thư tuyến giáp...

+ Các UTĐT do xâm lấn hoặc di căn từ nơi khác đến.

\subsection{Phương pháp nghiên cứu}

- Thiết kế nghiên cứu: Nghiên cứu mô tả cắt ngang hồi cứu kết hợp tiến cứu.

\section{- Thời gian và địa điểm nghiên cứu}

+ Thời gian nghiên cứu từ tháng 01/2018 đến tháng 12/2020.

+ Địa điểm nghiên cứu tại Bệnh viện Đa khoa tỉnh Nam Đinh.

- Phương pháp thu thập số liệu

+ Thu thập số liệu theo một mẫu bệnh án nghiên cứu thống nhất.

+ Tất cả các thông tin thu thâp từ hồ sơ bênh án.

2.3. Các phương pháp phẫu thuật cắt đại tràng phải:

- Phẫu thuât cắt nửa đại tràng phải, vét hạch: Được chỉ định cho ung thư từ manh tràng đến ĐT góc gan và phần phải ĐT ngang. Kỹ thuật bao gồm cắt đoạn cuối hồi tràng, manh tràng, đại tràng lên, ĐT góc gan và phần bên phải của ĐT ngang.

- Phẫu thuật cắt nửa đại tràng phải mở rộng: Chỉ định đối với UTĐT ngang bên phải đường giữa, cắt bán phần ĐT phải mở rộng với việc thắt hoàn toàn động mạch đại tràng giữa kèm cắt bỏ phần ĐT ngang bên trái động mạch này ít nhất $10 \mathrm{~cm}$.

\subsection{Biến số trong nghiên cứu}

Đặc điểm chung: tuổi, giới, nghề nghiệp, tiền sử bệnh lý bản thân và gia đình, bệnh lý nền, đặc điểm lâm sàng, cận lâm sàng, thời gian phẫu thuật, tai biến phẩu thuật; thời gian có trung tiện lại, số ngày dùng thuốc giảm đau, thời gian cho ăn lại,...Các biến biến chứng của phẫu thuật: biến chứng nhiễm trùng vết mổ, sì rò, bục miệng nối, viêm phổi,..tử vong sau mổ?

2.5. Phương pháp xử lý số liệu: Số liệu được xử lý trên phần mềm SPSS 16.0.

\section{KẾT QUẢ NGHIÊN CỨU VÀ BÀN LUÂ̂N}

Trong nghiên cứu chúng tôi thu thâp được 41 bênh nhân đủ tiêu chuẩn nghiên cứu có các đặc điểm chung sau: độ tuổi trung bình 62,9 $9 \pm 18,4$ tuổi, thấp nhất 24 tuổi, cao nhất 96 tuổi, nhóm tuổi thường gặp từ $61-80$ tuổi $(51,3 \%)$. Nữ $(63,4 \%)$ chiếm tỷ lệ nhiều hơn nam $(36,6 \%)$. Đô tuổi và tỷ lệ nữ trong nghiên cứu của chúng tôi đều cao hớn Dương Bá Lập (2018) [3] nhưng tương ứng tác giả Vajda K (2020). Nghề nghiệp phần lớn là lao động chân tay $87,8 \%$. Nơi ở chủ yếu ở nông thôn $85,4 \%$.

Bảng 1: Đăc điểm triệu chứng cơ năng và thức thể của bênh nhẩn UTETP

\begin{tabular}{|c|c|c|c|}
\hline \multicolumn{2}{|c|}{ Triệu chứng } & Số lượng & Tỷ lệ \% \\
\hline \multirow{9}{*}{$\begin{array}{c}\text { Triêu } \\
\text { chứng } \\
\text { cơ } \\
\text { năng }\end{array}$} & Đau bụng & 39 & 95,1 \\
\hline & Chán ăn & 4 & 9,8 \\
\hline & Gầy sút & 17 & 41,5 \\
\hline & Táo bón & 2 & 4,9 \\
\hline & Tiêu chảy & 12 & 29,3 \\
\hline & Phân nhày máu & 2 & 4,9 \\
\hline & Sốt & 11 & 26,8 \\
\hline & Nôn, buồn nôn & 8 & 19,5 \\
\hline & Bán tăc ruột & 11 & 26,8 \\
\hline \multirow{4}{*}{$\begin{array}{l}\text { Triệu } \\
\text { chứng } \\
\text { thực } \\
\text { thể }\end{array}$} & Sờ thấy u ở bụng & 28 & 68,3 \\
\hline & Thiếu máu & 16 & 39,0 \\
\hline & Tắc ruột & 9 & 22,0 \\
\hline & Viêm phúc mạc & 10 & 24,4 \\
\hline
\end{tabular}

Nhận xét: Triệu chứng cơ năng là những gợi ý đầu tiên giúp người thầy thuốc chú ý khi thăm khám để có hướng chẩn đoán và quyết định xét nghiệm cận lâm sàng. Trong nghiên cứu của chúng tôi $95,1 \%$ bệnh nhân có triệu chứng đau bụng, $41,5 \%$ bệnh nhân gây sút, $26,8 \%$ bệnh nhân có triệu chứng bán tắc ruột, 29,3\% bệnh nhân tiêu chảy, 4,9\% bệnh nhân táo bón. Kết quả nghiên cứu của chúng tôi tương tự như Dương Bá Lập (2018) [3]. Ngoài ra trong nghiên cứu của chúng tôi có $26,8 \%$ bệnh nhân có sốt, $19,5 \%$ bệnh nhân có nôn và buồn nôn. Khám thực thể có $68,3 \%$ sờ thây u ở bụng, $39,0 \%$ thiếu máu, $24,4 \%$ viêm phúc mạc, $22,0 \%$ có tắc ruột. Tỷ lệ bệnh nhân có biến chứng cấp cứu (tắc ruột, viêm phúc mạc) trong nghiên cứu của chúng tôi tương ứng như nghiên cứu của Chử Quốc Hoàn và cộng sự (2020) [2] với 24,0\% bệnh nhân có biến chứng cấp cứu.

Bảng 2: Đặc điểm khối u của bệnh nhân UTDTP

\begin{tabular}{|c|c|c|c|}
\hline \multicolumn{1}{|c|}{ Đặc điếm khối u đại tràng } & $\begin{array}{c}\text { Số } \\
\text { phải }\end{array}$ & $\begin{array}{c}\text { Tỷ lệ } \\
\text { lượng }\end{array}$ \\
\hline \multirow{3}{*}{ Vị trí u } & Manh tràng & 20 & 48,8 \\
\cline { 2 - 4 } & Đại tràng lên & 8 & 19,5 \\
\cline { 2 - 4 } & Đại tràng góc gan & 11 & 26,8 \\
\hline
\end{tabular}


VIETNAM MEDICAL JOURNAL N²2 - AUGUST - 2021

\begin{tabular}{|c|c|c|c|}
\hline & $\begin{array}{c}\text { Đại tràng ngang } \\
\text { bên phải }\end{array}$ & 2 & 4,9 \\
\hline \multirow{3}{*}{$\begin{array}{l}\text { Kích } \\
\text { thước u }\end{array}$} & $\begin{array}{l}\text { TB } \pm \text { ĐLC } \\
(\text { Min-Max }) \\
\end{array}$ & \multicolumn{2}{|c|}{$\begin{array}{c}6,4 \pm 1,9 \\
(4-10)\end{array}$} \\
\hline & $<5 \mathrm{~cm}$ & 6 & 14,6 \\
\hline & $\geq 5 \mathrm{~cm}$ & 35 & 85,4 \\
\hline \multirow{4}{*}{$\begin{array}{l}\text { Độ xâm lấn } \\
\text { của khối u }\end{array}$} & $T_{2}$ & 3 & 7,3 \\
\hline & $T_{3}$ & 4 & 9,8 \\
\hline & $T_{4 a}$ & 20 & 48,8 \\
\hline & $T_{4 b}$ & 14 & 34,1 \\
\hline \multirow[b]{2}{*}{ Đếm hạch } & Có đếm & 38 & 92,7 \\
\hline & Không đếm & 3 & 7,3 \\
\hline \multirow{3}{*}{$\begin{array}{l}\text { Mức độ di } \\
\text { căn hạch } \\
(\mathrm{n}=38)\end{array}$} & $\mathrm{N}_{0}$ & 23 & 60,5 \\
\hline & $\mathrm{N}_{1}$ & 14 & 36,9 \\
\hline & $\mathrm{N}_{2}$ & 1 & 2,6 \\
\hline $\begin{array}{l}\text { Mức độ di } \\
\text { căn xa }\end{array}$ & $M_{0}$ & 41 & 100 \\
\hline \multirow{3}{*}{$\begin{array}{l}\text { Giai đoạn } \\
\text { bệnh } \\
(n=38)\end{array}$} & I & 2 & 5,3 \\
\hline & II & 21 & 55,3 \\
\hline & III & 15 & 39,4 \\
\hline
\end{tabular}

\begin{tabular}{|c|c|c|c|}
\hline \multirow{5}{*}{ Đại thể } & Sùi & 27 & 65,9 \\
\hline & Loét & 2 & 4,9 \\
\hline & Thâm nhiềm & 4 & 9,8 \\
\hline & Polyp K hóa & 1 & 2,4 \\
\hline & Kết hợp & 7 & 17,0 \\
\hline $\begin{array}{l}\text { Số hạch } \\
\text { thu được }\end{array}$ & $\begin{array}{l}\text { TB } \pm \text { ĐLC } \\
\text { (Min-Max) }\end{array}$ & \multicolumn{2}{|c|}{$\begin{array}{c}10,4 \pm 2,5(7- \\
18)\end{array}$} \\
\hline $\begin{array}{l}\text { Số hạch } \\
\text { dương tính }\end{array}$ & $\begin{array}{l}\text { TB } \pm \text { ĐLC } \\
\text { (Min-Max) }\end{array}$ & \multicolumn{2}{|c|}{$0,9 \pm 1,2(0-4)$} \\
\hline \multirow{3}{*}{ Vi thể } & $\begin{array}{l}\text { Ung thư biếu } \\
\text { mô tuyến }\end{array}$ & 39 & 95,2 \\
\hline & U GIST & 1 & 2,4 \\
\hline & $\begin{array}{c}\text { U Lympho ác } \\
\text { tính }\end{array}$ & 1 & 2,4 \\
\hline \multirow{3}{*}{$\begin{array}{c}\text { Đô̂ biệt } \\
\text { hóa } \\
(n=39)\end{array}$} & Cao & 14 & 35,9 \\
\hline & Vừa & 16 & 41,0 \\
\hline & Thấp & 9 & 23,1 \\
\hline
\end{tabular}

Nhận xét: Hình ảnh đại thể giải phẫu bệnh trong nghiên cứu hay gặp nhất là thể sùi với $65,9 \%$, tiếp đến là thể kết hợp $17,0 \%$ (7,3\% sùithâm nhiễm, $2,4 \%$ sùi-polyp $\mathrm{K}$ hóa, $7,3 \%$ sùiloét), 9,8\% thể thâm nhiễm, 4,9\% thể loét, thấp nhất $2,4 \%$ là thể polyp $K$ hóa. Kết quả nghiên cứu phù hợp với tác giả Lê Huy Hòa (2011) [1] thể sùi chiếm tỷ lệ cao với 78\%, theo Đặng Công Thuận và cộng sự (2012) [5] thể sùi trong UTĐT chiếm tỷ lệ 83,6\%.

Theo mang lưới ung thư quốc gia Hoa Kỳ và các trung tâm ung thư trên thế giới đều thống nhất số lượng hạch vùng phẫu tích từ các bệnh phẩm phẫu thuật UTĐT là nhiều hơn hoặc bằng 12 hạch, như vậy phân loại hạch mới được chính xác và chỉ cân 1 hạch dương tính là UTĐT được xếp vào giai đoạn III [9]. Số hạch trung bình thu được trong nghiên cứu là 10,4 $\pm 2,5$ hạch, thấp nhất 7 hạch và cao nhất 18 hạch. Giải phẫu bệnh vi thể cho thây có $95,2 \%$ trường hợp ung thư biểu mô tuyến, u GIST và u Lympho ác tính đều là $2,4 \%$. Độ biệt hóa cao, vừa đềuvà thấp lần lượtlà $35,9 \%, 41,0 \%$ và $23,0 \%$. Nghiên cứu của Huscher C.G và cộng sự (2012) [7] có tỷ lệ tương đồng nghiên cứu của chúng tôi với độ biệt hóa vừa chiếm tỷ lệ cao nhất $62,0 \%$, biệt hóa cao $25,0 \%$ và biệt hóa kém $13,0 \%$.

mổ của bệnh nhân UTĐTP
\begin{tabular}{|c|c|c|}
\hline Giải phẫu bệnh sau mổ & $\begin{array}{c}\text { Số } \\
\text { lượng }\end{array}$ & $\begin{array}{c}\text { Tỷ lệ } \\
\%\end{array}$ \\
\hline
\end{tabular}

Bảng 4: Một số kêt quả sớm sau phẫu thuật của bệnh nhân UTĐTP

\begin{tabular}{|c|c|c|c|c|}
\hline $\begin{array}{c}\text { Đắc điếm phâu thuật } \\
\text { TB } \pm \text { ĐLC (Min-Max) }\end{array}$ & $\begin{array}{c}\text { Chung } \\
\mathbf{n = 4 1}\end{array}$ & $\begin{array}{c}\text { Mố mở } \\
\mathbf{n = 3 6}\end{array}$ & $\begin{array}{c}\text { Mố nội soi } \\
\mathbf{n = 5}\end{array}$ & $\mathbf{p}$ \\
\hline Thời gian mổ (phút) & $\begin{array}{c}122,6 \pm 28,5 \\
(80-180)\end{array}$ & $\begin{array}{c}123,3 \pm 29,0 \\
(80-180)\end{array}$ & $\begin{array}{c}118,0 \pm 26,6 \\
(80-150)\end{array}$ & $>0,05$ \\
\hline $\begin{array}{c}\text { Thời gian dùng giảm đau } \\
\text { sau mổ (ngày) }\end{array}$ & $\begin{array}{c}3,8 \pm 0,7 \\
(2-5)\end{array}$ & $\begin{array}{c}3,9 \pm 0,6 \\
(3-5)\end{array}$ & $\begin{array}{c}2,8 \pm 0,4 \\
(2-3)\end{array}$ & 0,004 \\
\hline $\begin{array}{c}\text { Thời gian có nhu động } \\
\text { ruột sau mổ (ngày) }\end{array}$ & $\begin{array}{c}3,1 \pm 0,6 \\
(2-4)\end{array}$ & $\begin{array}{c}3,1 \pm 0,6 \\
(2-4)\end{array}$ & $\begin{array}{c}2,8 \pm 0,4 \\
(2-3)\end{array}$ & $>0,05$ \\
\hline
\end{tabular}




\begin{tabular}{|c|c|c|c|c|}
\hline $\begin{array}{c}\text { Thời gian nằm viện sau } \\
\text { mổ (ngày) }\end{array}$ & $\begin{array}{c}10,6 \pm 2,8 \\
(6-21)\end{array}$ & $\begin{array}{c}10,8 \pm 2,9 \\
(8-21)\end{array}$ & $\begin{array}{c}9,2 \pm 1,8 \\
(6-10)\end{array}$ & $>0,05$ \\
\hline
\end{tabular}

Nhân xét: Trong nghiên cứu có 36 bênh nhân mổ mở và 5 bênh nhân mổ nọi soi. Thời gian mổ trung bình là $122,6 \pm 28,5$ phút, thấp nhất 80 phút và cao nhất 180 phút. Thời gian mổ giữa 2 phương pháp mổ mở và mổ nội soi gần như tương ứng.

Thời gian có nhu động ruột sau mổ trung bình là $3,1 \pm 0,6$ ngày, sớm nhất là 2 ngày và muộn nhất là 4 ngày. Trong nghiên cứu của chúng tôi, bệnh nhân được cho ăn trở lại ngay khi có nhu động ruột và được xác định bằng bệnh nhân có trung tiện. Thời gian dùng giảm đau sau mổ trung bình là $3,8 \pm 0,7$ ngày, ít nhất là 2 ngày và nhiêu nhất là 5 ngày. Thời gian trung bình dùng giảm đau sau mổ ở phương pháp mổ nội soi $(2,8 \pm 0,4)$ ít hơn hẳn so với mổ mở $(3,9 \pm 0,6)$ với $p<0,005$. Theo Nguyễn Thi Kim Thu và cộng sự [4], mức độ đau sau mổ có liên quan mật thiết với độ dài đường mở bụng và mức độ phấu tích các tạng trong ổ bung, so với mổ mở, mổ nội soi chỉ có vết mổ nhỏ ở thành bụng, mức độ phẫu tích cũng nhẹ nhàng và gây sang chấn tối thiểu. Bên cạnh đường mở bụng để đưa bệnh phẩm ra ngoài và hỗ trợ khâu nối giống như mổ nội soi cắt đại tràng kinh điển thì mổ nội soi giảm bớt được chiều dài rạch da, cân và phúc mạc do đó hạn chế được đau sau mổ cho bệnh nhân, giúp bệnh nhân sớm trở lại sinh hoạt và lao động cũng như có tính thẩm mỹ cao.

Thời gian nằm viện sau mổ trung bình là 10,6 $\pm 2,8$ ngày, ngắn nhất là 6 ngày và dài nhất là 21 ngày. Mặc dù không có sự khác biệt giữa thời gian nằm viện trung bình ở 2 phương pháp phẫu thuật nhưng trong nghiên cứu của chúng tôi thời gian nằm viên trung bình sau mổ nội soi $9,2 \pm$ 1,8 ngày ngắn hơn thời gian nằm viện trung bình sau mổ mở 10,8 $\pm 2,9$ ngày.

Bảng 5: Đặc điểm biến chứng và mổ lại của bênh nhẩn UTOTP

\begin{tabular}{|c|c|c|c|}
\hline \multicolumn{2}{|c|}{ Biến số } & $\begin{array}{c}\text { Số } \\
\text { lượng }\end{array}$ & $\begin{array}{c}\text { Tỷ lệ } \\
\text { \%o }\end{array}$ \\
\hline \multirow{2}{*}{$\begin{array}{c}\text { Biến } \\
\text { chứng } \\
\text { sau mổ }\end{array}$} & Không biến chứng & 34 & 82,9 \\
\cline { 2 - 4 } & Nhiếm trùng vết mố & 6 & 14,6 \\
\cline { 2 - 4 } & Bí tiếu & 1 & 2,4 \\
\hline \multicolumn{2}{|c|}{ Mố lại } & 1 & 2,4 \\
\hline \multicolumn{2}{|c|}{ Lý do } & \multicolumn{2}{c|}{ Toác vết mố } \\
\hline
\end{tabular}

Nhân xét: Trong nghiên cứu của chúng tôi có $100 \%$ bệnh nhân không bị tai biến trong phẫu thuật và $82,9 \%$ không gặp biến chứng sau phẫu thuật. Bên cạnh đó nghiên cứu có $14,6 \%$ trường hợ bi nhiễm trùng vết mổ, được lấy dich vết mổ cấy khuẩn và điều trị theo kháng sinh đồ, $2,4 \%$ trường hợp bị bí tiểu, không có trường hợp nào bị sì rò bục miệng nối. Có 1 trường hợp mổ lại do nhiểm trùng vết mổ gây ra toác vết mổ, đã được phẫu thuật đóng lại vết mổ, điều trị kháng sinh theo kháng sinh đồ, tăng cường dinh dương, bệnh nhân sau đó ổn định ra viện sau 10 ngày.

\section{KẾT LUÂ̂N}

Phẫu thuật cắt đại tràng phải do ung thư tại Bênh viên Đa khoa tỉnh Nam Định giai đoạn 2018-2020 cho kết quả sớm tương đối tốt:không có tai biến phẫu thuật, không có tử vong sau mổ, thời gian dùng giảm đau sau mổ ở nhóm mổ nội soi ít hơn so với nhóm mổ mở, thời gian cho ăn lại và thời gian nằm viện sau mổ chấp nhận được, một số nhiễm trùng vết mổ được điều trị nội khoa.

\section{TÀI LIÊU THAM KHẢO}

1. Lê Huy Hòa (2011), "Nghiên cứu sự di căn hạch trong ung thư đai tràng", Y Hoc TP. Hồ Chí Minh, tập 15, Phụ bản của Số 4, tr. 40 - 44.

2. Chử Quốc Hoàn, Nguyễn Tiến Quang và Nguyễn Vă̆n Hiếu (2020), "Đánh giá bước đâu kêt quả phẩu thuật mở cắt toàn bô mac treo đai tràng, điêu tri ung thư đai tràng giai đoan II-III, tại Bệnh viện K", Tap chí Y hoc Quân sự, tr. 12-18.

3. Dướng Bá Lập (2018), "Kết quả sớm sau phẫu thuật nội soi cắt toàn bộ mạc treo đại tràng trong điều trị ung thư đại tràng phải", Hội nghị khoa học kỹ thuât lấn thứ 35 Đại học Y Dược TP.Hồ Chí Minh, trî. 11-16

4. Nguyê̂n Thi Kim Thu, Pham Văn Bình và Nguyển Văn Hiếu (2010), Só sánh mức độ đau sau phẫu thuật nội soi và mổ mở ung thư đại trực tràng tại khoa ngoại C, Y Học TP. Hồ Chí Minh, 14(4), tr. $760-764$.

5. Đăng Công Thuận, Nguyễn Duy Nam Anh (2012), Nghiên cưuu mối liên quan giữa nồng độ CEA và các đắc điểm lâm sàng, giải phẫu bênh trong ung thư biểu mô đại trực tràng, Tạp chí $Y$ Dược hoc (9), tr. 86-95.

6. Bray F., Ferlay J., Soerjomataram I., et al. (2018). Global cancer statistics 2018: GLOBOCAN estimates of incidence and mortality worldwide for 36 cancers in 185 countries. CA Cancer J Clin, 68(6), p. 394-424.

7. Hubner $\mathbf{M}$, Demartines $\mathbf{N}$, Muller S., et al. (2008), Prospective randomized study of monopolar scissors, bipolar vessel sealer and ultrasonic shears in laparoscopic colorectal surgery, British J. of Sur, (95), p. 1098-1104.

8. Kalantzis I., Nonni A., Pavlakis K., et al. (2020). Clinicopathological differences and correlations between right and left colon cancer. World J Clin Cases, 8(8), p. 1424-1443.

9. NCCN (2019), National Comprehensive Cancer Network guidelines Pratice guidline in Oncology, Colon cancer. 